\title{
EXPERIENCE AND REFLECTION ON AN INTEGRATED MATHEMATICS CURRICULUM FOR AN ENGINEERING Articulation Program
}

\author{
R.W. Brennan, K. Johnston, S. Li, N. Nelson, A. Nygren, R. Paul, and M. Sullivan \\ Schulich School of Engineering, University of Calgary \\ rbrennan@ucalgary.ca
}

\begin{abstract}
In this paper, we provide an overview of an integrated mathematics curriculum that is a key element of an engineering articulation program (polytechnic to university). This integrated approach to teaching mathematics is a logical extension of the integrated curriculum models that have been gaining popularity for undergraduate engineering education since the 1960's, and is well suited to the fast-paced nature of an engineering articulation program. We provide background on the engineering articulation program and the integrated mathematics curriculum, and provide reflections on the implementation of this approach.
\end{abstract}

Keywords: engineering articulation programs; mathematics education; curriculum design; integrated curriculum

\section{INTRODUCTION}

In 2015 a new B.Sc. in Energy Engineering program was introduced at the University of Calgary's Schulich School of Engineering to provide graduates of technology diploma programs with a seamless transition to a university engineering degree program. In total, graduates of the B.Sc. in Energy Engineering take 4-years of postsecondary education ( 2 years at a polytechnic plus 2 years at the Schulich School of Engineering). Graduates hold a degree from each institution: both a technology diploma (normally focused in mechanical, chemical, petroleum, or power engineering technology) and a B.Sc. in Energy Engineering. Although there are many distinctive aspects of this program, this paper will focus on the unique approach to the mathematics curriculum.

The B.Sc. in Energy Engineering program was carefully designed for student success, recognizing that students in this program have a different starting point from that of the university's high school admitted students. More specifically, graduates of polytechnic programs arrive with a background in a variety of engineering science topics, but do not have the natural science and mathematics foundation that is typically delivered in a first-year undergraduate engineering program. B.Sc. in Energy Engineering students indicate the transition from polytechnic to university is challenging in particular in mathematics. While the students take calculus-based mathematics as part of their engineering technology program, university courses expect a higher level of ability to apply these skills for problem solving. In this paper, we describe the curriculum design process we followed to address this challenge and reflect on our experience with this approach.

We start with an overview of the integrated mathematics curriculum, and then provide reflections on its implementation, and the evolution of its design. Although the integrated mathematics approach was developed to tailor to our B.Sc. in Energy Engineering students, this paper provides insight into the pedagogical approach, and provides recommendations on how it could be useful for student learning in other engineering programs.

\section{BACKGROUND}

The B.Sc. in Energy Engineering curriculum presented a number of unique curriculum design challenges related primarily to fundamental differences in polytechnic and undergraduate engineering curricula, as well as the desire for an accelerated " $2+2$ " program. Like most other undergraduate engineering programs in North America, the Schulich School of Engineering's programs follow the engineering science structure that evolved after World War II [13] where first year consists primarily of foundational natural science and mathematics courses. Given that graduates of technology programs do not take these foundation courses in their two-year diploma programs, the path to an engineering undergraduate degree would typically require first completing these natural science and mathematics courses before senior engineering science and design courses could be attempted. This resulted in at least three years of study beyond a polytechnic diploma.

Unlike other college articulation programs in Canada (e.g., Lakehead University's College Transfer program [21], Camosun College's Engineering Bridge program [5], Conestoga's Bridging pathways [8]), the B.Sc. in Energy Engineering program involves direct admission 
upon completion of a polytechnic program and does not include a bridge program. The curriculum design challenge we faced was thus: how could we embed this foundation in natural science and mathematics within a two-year program?

As noted previously, the one key consideration was to provide the necessary mathematics foundations. All engineering technology programs considered for this articulation program did include a course in singlevariable integral and differential calculus, however this was the extent of mathematical training in most cases, and as a result, had to be considered the minimum path for admission. As well, a detailed review of the engineering technology program curricula and course materials revealed that these programs placed much less emphasis on the application of calculus to the solution of natural and engineering science problems than is common in undergraduate engineering programs.

Clearly mathematics plays an important, if not central, role in engineering education. In 1904, Waldo characterized mathematics as "the very bone and sinew of an engineering course" [23]. This sentiment has been echoed over the years by various authors (e.g., Hundhausen and Yeatts [14], Kumar and Jalko [20], Klingbeil et al. [19], Karney and Mather [17], Gollish and Karney [12], Gollish [11]) and, anecdotally, over many coffee chats with engineering faculty.

In addition to agreeing on the importance of mathematics to the education of future engineers, there is also consistent agreement on the challenges associated with this aspect of the curriculum. Concerns about students' preparedness - and in particular, their precalculus skills - have persisted for more than a century. For example, Waldo's concerns about secondary mathematics education in 1904 would not be out of place in Hundhausen's 1995 paper where pre-calculus skills are identified as a barrier to student learning [14]. Engineering mathematics is unique in that it is a "blend of both the abstract and applied disciplines of mathematics" [11].

However, secondary (pre-university) preparation in mathematics is not, and should not, be the sole focus of concern. A common theme in the literature on engineering mathematics education relates to "transferability", student's difficulties transferring mathematical concepts to various contexts or applications [14]. This challenge was also noted by Schoenfeld in his studies of students' problem-solving skills in mathematics [22].

To address this challenge and to promote transferability, engineering educators recognize the need to show the connections between mathematical principles and engineering science/design. For example, a program called "Engineering First" was developed at Northwestern University, where linear algebra and differential equations instruction is integrated with mechanics, circuits, and communication networks [4].

A similar program was developed as part of the National Science Foundation's 1988-1993 "Calculus Reform Initiative" at the Colorado School of Mines. They developed a first-year mathematics curriculum where course material is taught in a modular style, alternating between calculus and physics: i.e., introduction of a mathematical concept, followed by a set of graduated examples or applications [14]. In a three-year study that measured student achievement in subsequent courses, the authors observed significantly better performance by students in the integrated mathematics program [14].

These initiatives can be thought of in the context of the integrated curriculum models that have been gaining popularity since the 1960 's: i.e., "programs to help students make more and stronger connections among mathematics, science, and engineering" [10]. Early examples of these integration efforts include Harvey Mudd College in the 1960's and Worcester Polytechnic Institute in the 1970's. In the area of mathematics, examples include [1], [4], [7], [14], [19], and [20].

Without integrated curriculum, students view mathematics as irrelevant to engineering, because the connection is not clear to them [1]. Whereas the integrated mathematics approach can in fact improve student success as demonstrated by the Colorado School of Mines study described above [14]. Sasha Gollish's $2019 \mathrm{PhD}$ thesis used a mixed methods study to review the engineering mathematics curriculum [11]. In her findings, she recommends four changes to the way we teach mathematics in engineering: 1) use more metacognition in teaching mathematics; 2) give more examples to help students create connections between mathematics and engineering; 3) integrate mathematics with engineering examples; and 4) create a skills map to link mathematics skills to engineering concepts [11]. When mathematics is taught alongside engineering, students can organize their knowledge around big ideas, concepts, and themes which improves their ability to engage in deep learning and apply to real-world circumstances [18].

As noted previously, we chose to take an "integrated mathematics" approach when designing the B.Sc. in Energy Engineering curriculum. The primary aim was to develop a curriculum that promoted transferability of mathematical principles to engineering science and design. As well, we felt this approach fit best with the rapid pace of the B.Sc. in Energy Engineering program (i.e., a " $2+2$ " articulation program with the polytechnic). In the next section we describe the B.Sc. in Energy Engineering's mathematics curriculum. 


\section{THE INTEGRATED MATHEMATICS CURRICULUM}

The B.Sc. in Energy Engineering program uses an "integrated mathematics" curriculum that follows a "just in time" model where the students learn mathematical concepts in the same course where the mathematical concepts are applied in engineering applications. This approach has parallels to the Wright State approach that follows "an application-oriented, hands-on approach [addressing] only the salient mathematics topics actually used in a variety of core engineering courses" [19]. This pedagogical approach reduces the challenges of mathematics segregated from engineering, where there is no connection made between the mathematics students are required to learn and their engineering courses [1]. As Dodson [9] notes, "engineering and science students always wish to perceive relevance in the topics they study and nowhere is their sensitivity more acute than in the mathematical service courses they receive."

This integrated mathematics approach is intended to enhance the students' engagement with the material and to promote deeper learning of the material. Student engagement and motivation can be increased when the material is contextualized in a way that students see the "real world" applications of the course material. In our integrated mathematics courses, students are taught a practical application of the mathematics content shortly after learning the mathematics concept itself.

The B.Sc. in Energy Engineering's integrated mathematics curriculum is shown in Fig. 1. Rows represent each term of the two-year program (chronologically from top to bottom), and columns represent the CEAB (Canadian Engineering Accreditation Board) mathematics topics: i.e., criterion 3.4.3.1 of the CEAB's 2019 Accreditation Criteria and Procedures that notes:

"Mathematics is expected to include appropriate elements of linear algebra, differential and integral calculus, differential equations, probability, statistics, numerical analysis, and discrete mathematics." [6]

In this figure we show regular mathematics courses with a white background. By "regular" we mean mathematics courses that focus exclusively on mathematical concepts. For example, MATH 209 "Applied and Computational Linear Algebra for Energy Engineers" covers systems of linear equations, matrices and matrix operations, determinants, and vectors; this course also includes numerical analysis material related to calculations on matrices. ENGG 319 "Probability and Statistics for Engineers" is the Schulich School of Engineering's common core probability and statistics course, taken by engineering students across all undergraduate programs.

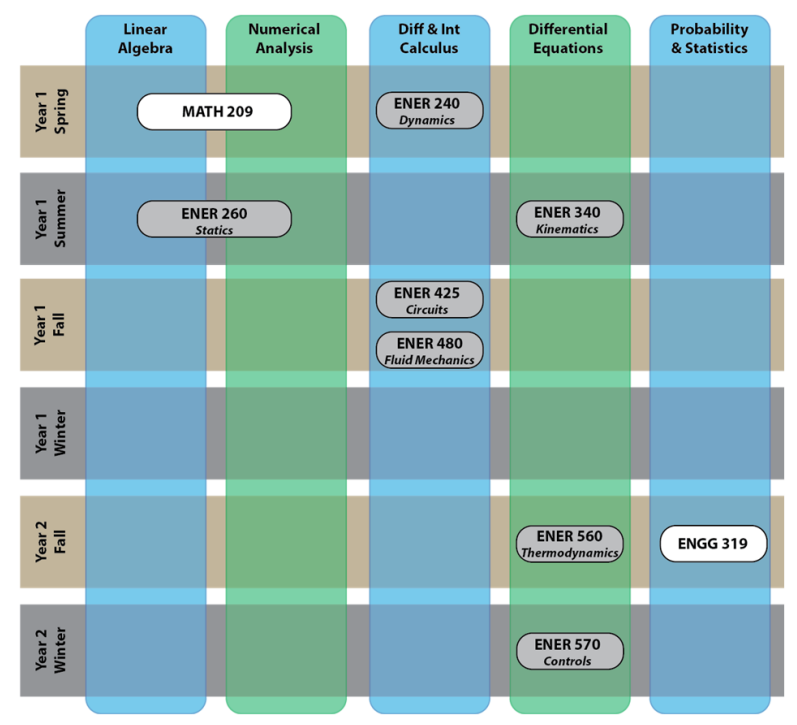

Fig. 1. The B.Sc. in Energy Engineering integrated mathematics curriculum.

The integrated mathematics courses are shown in gray in Fig. 1, with the corresponding engineering science topic shown in italics. For example, B.Sc. in Energy Engineering students are taught ordinary differential equations in ENER 340 "Dynamics for Energy Engineering I". This includes the typical topics in a first course on differential equations such as definition, existence and uniqueness of solutions, and first order and higher order equations. However, the pedagogical approach differs from a "regular" differential equations course in its modular teaching style. More specifically, mathematical concepts are introduced, and the theory is discussed along with mathematical examples. This is then closely followed by examples and applications tied to the engineering science material. In the case of ENER 340 "Dynamics for Energy Engineering I", students are introduced to different types of ordinary differential equations, which they are then required to apply to developing models of dynamic systems; they are taught new analytical techniques to solve ordinary differential equations of different orders, which they can immediately apply to the analysis of rigid body dynamics problems in kinetics; etc.

As shown in Table 1, the B.Sc. in Energy Engineering program (ENER) compares favorably to the Schulich School of Engineering's regular, high-school admission undergraduate engineering programs (HS), in terms of mathematics curriculum coverage. ENER students complete a total of ten 3-credit courses with mathematics content (nine at the Schulich School of Engineering plus one at the polytechnic), compared to six 3-credit courses for students in our regular programs. In this table, we identify both courses with integrated mathematics (Int.) 
and regular mathematics (Reg.). The larger number of ENER mathematics courses is required to ensure that the program meets the $\mathrm{CEAB}$ accreditation unit (AU) criterion for mathematics given that seven of the nine courses with mathematics content are integrated. For these courses the mathematics AU proportions range from $25 \%$ to $45 \%$.

\section{REFLECTING ON THE CURRICULUM}

The initial work on the B.Sc. in Energy Engineering curriculum began in the 2013/2014 academic year following a series of discussions with Alberta higher education institutions associated with the Alberta Council on Admissions and Transfer (ACAT) [2]. At the time, there was no formal pathway for a technical diploma graduate (from a polytechnic) to an undergraduate engineering degree. Students who wanted to enrol in an engineering program found that their technology diploma had little impact on the length of their program. Typically, an additional three to four years was still required after the diploma. In the spirit of the "Campus Alberta" initiative promoted by the provincial government around 2013 [3], there was growing interest in creating new and improved pathways to higher education in the province, and shortening the polytechnic-to-university pathway was a central theme of these discussions.

Table 1: Courses with mathematics content by CEAB topics and course type (int $=$ integrated or reg $=$ regular).

\begin{tabular}{|c|c|c|c|}
\hline & \multicolumn{2}{|c|}{ ENER } & $\mathrm{HS}^{\mathrm{a}}$ \\
\hline & Int. & Reg. & Reg. \\
\hline Linear Algebra & \multirow{2}{*}{$1^{b}$} & \multirow{2}{*}{$1^{\mathrm{b}}$} & 1 \\
\hline Numerical Analysis & & & 1 \\
\hline Diff. \& Int. Calculus & 3 & $1^{\mathrm{c}}$ & 2 \\
\hline Differential Equations & 3 & 0 & 1 \\
\hline Probability \& Statistics & 0 & 1 & 1 \\
\hline TOTAL & & & 6 \\
\hline
\end{tabular}

Notes:

a. High School admission programs

b. Courses which cover both Numerical Analysis and Linear Algebra (Fig. 1)

c. Credit for single variable calculus taken at the polytechnic

The integrated mathematics approach described in this paper was first implemented in the 2015/2016 academic year and was a direct outcome of these factors. In this section, we reflect on the resulting curriculum.

\subsection{Pre-calculus Foundations}

Although the Schulich School of Engineering fully supported the creation of new pathways, we recognized that a shorter university program would come with challenges. As noted previously, we anticipated the main challenge would be in the area of mathematics education given differences in the curriculum structure between technical diploma programs and undergraduate engineering programs. Our assumption in this regard was correct; however, we did not anticipate the extent to which pre-calculus preparedness would play a role in this challenge.

For more than a century, engineering educators have argued that a strong foundation in algebra, trigonometry, and geometry is essential to success in an undergraduate engineering program. Yet, to this day, there are concerns about students' facility with these essential mathematical skills. This presents a barrier to all undergraduate engineering students; however, we found it to be particularly problematic for students in the B.Sc. in Energy Engineering program given the fast pace of the program as well as variations in student backgrounds (given that students are admitted from a variety of technology programs).

To address this concern, we added a pre-calculus refresher course to the curriculum for the program's second cohort in 2016/2017, then followed this up in $2017 / 2018$ with a regular mathematics course, MATH 209 "Applied and Computational Linear Algebra for Energy Engineers" that is offered during the first term of the program. This combination of a pre-calculus course and a regular mathematics course at the beginning of the program provided students with a strong introduction to university-level mathematics and served as a foundation for the integrated mathematics courses that follow.

In addition to the required pre-calculus foundations course MATH 209, we found many students coming from a polytechnic have not done math problems for at least one-year, and often longer. For this reason, we added an optional "mathematics boot camp" in advance of the start of the semester. This course provides a refresher on basic mathematics concepts, such as trigonometry, polynomials, and difficult equation manipulation. Usually about half the students attend a portion of the mathematics boot camp to get back into a mathematics mindset prior to their first semester. Student feedback on the boot camp was very positive, and they found it extremely helpful to their success in their first few courses. One criticism after the first year was to ensure the math topics covered were more directly applicable to the knowledge they would need in their first few semesters, and we have since adjusted the content.

\subsection{The Interpretation of "Mathematics"}

The introduction of integrated mathematics courses in the B.Sc. in Energy Engineering program resulted in some very interesting discussions around the interpretation of "mathematics", particularly in the context of the CEAB's curriculum content categories. For example, given the blending of mathematics with engineering science in these courses (i.e., the modular approach described by 
Hundhausen et al. [14]), there was confusion around how much of the course content related to "mathematics" versus how much of the course content related to "engineering science". This confusion has the potential of impacting how one interprets the integrated mathematics course's accreditation unit (AU) count. As noted in criterion 3.4.4.2 of the CEAB's 2019 Accreditation Criteria and Procedures:

"Engineering science subjects involve the application of mathematics and natural science to practical problems. They may involve the development of mathematical or numerical techniques, modeling, simulation, and experimental procedures." [6]

It is unlikely this same confusion would exist around natural science and engineering science, since a common interpretation of engineering is that "engineering" is the application of science to practical problems. For example, an introductory materials course can contain both natural science subjects (e.g., structure of materials, atomistic models) and engineering science subjects (e.g., thermalmechanical processing, microstructure formation and control), and as such can include AUs in both natural science and engineering science. However, we found there is confusion separating mathematics subjects from engineering science subjects in an integrated mathematics course even though criterion 3.4.4.2 notes that "engineering science subjects involve the application of mathematics".

This is a fundamental misunderstanding between curriculum and pedagogy. When evaluating the curriculum content of a course, one should look at the curricular elements (subjects) in the context of the CEAB definitions. For example, introducing students to atomistic models is clearly natural science; introducing students to ordinary differential equations is clearly mathematics. However, when the knowledge of atomistic models is applied to the practical problem of changing a material's microstructure, or the ordinary differential equation is used to model a dynamic system, the subject is clearly engineering science.

It shouldn't matter if these subjects are introduced in separate courses, or if they are introduced within the same "integrated curriculum" courses. The distinction is the same. However, as discussed in this paper, one may make choices around how these subjects are taught in order to achieve the best outcome for the students. This is a matter of pedagogy and should not be confused with curriculum.

\subsection{Course Assignment}

When implementing the B.Sc. in Energy Engineering program, we had to consider the selection of course instructors for the integrated mathematics courses. Like any new curriculum initiative, it is important to have a core group of faculty who have "bought in" involved in the delivery of the initiative, and ideally, have this enthusiasm spread to other faculty members.

For the B.Sc. in Energy Engineering program, we did not have this core group given the nature of the program's development. As noted previously, this program was initiated in response to provincial priorities (Campus Alberta, ACAT). Unlike many other Schulich School of Engineering curriculum initiatives, it was not a grass roots, departmental initiative. Despite this, enthusiasm for the integrated curriculum approach grew as the program was developed and implemented.

However, not all faculty members were comfortable teaching mathematics. This came as a surprise to many of us given that faculty often comment on their students' mathematics background (e.g., insufficient coverage of certain topics, insufficient depth on other topics, and/or too much coverage on other, unrelated, topics). Our naïve view on this approach was that faculty would enjoy having more direct control over not only what mathematics topics were covered, but also where the emphasis was placed and how the material was reinforced in the context of engineering applications.

This reluctance to teach mathematics is not the case for all faculty members. For example, some find the approach lends itself very nicely to course learning objectives: in ENER 570 "Automation and Controls", including differential equations (linear time invariant systems, Laplace transform solutions) matches very well with modelling and control, allowing the instructor to ensure students develop the mathematics skills needed to tackle the engineering science topics in the course.

As part of our continual improvement process, we are currently exploring a model where the integrated mathematics courses are co-taught by a faculty member from the mathematics department and an engineering faculty member. We piloted this co-teaching model with ENER 480 "Energy Engineering Fluid Mechanics" during the Fall 2019 term. Although we did not formally receive student feedback for the purpose of research, we can provide some anecdotal reflections on this pilot project. The students mentioned that having two instructors make it sometimes feel like it was two separate courses that were jumping back and forth, and often perceived the course to have a high course load. On the flip side, the students did appreciate the math instructor's expertise, and ability to use clear mathematical language and examples to explain the concepts.

\subsection{Mathematics Skills Reconsidered}

The final observation extends as a result of discussions that have come from the previous section (e.g. who is responsible for teaching mathematics). In discussing the integrated mathematics approach at different venues, we hear some comments that the mathematics content should be taught by mathematicians since they are subject matter experts. This comment 
implies that engineers should not teach mathematics at a university level. Further, we assume many engineering schools rely on faculty from mathematics departments to deliver mathematics content in engineering programs. Beyond the discussion about the qualification of the instructor's background, a more fundamental consideration should be about what mathematics skills we want our engineering students to demonstrate in school (e.g., prove mathematics expressions and do double integrals?). The answer to this question will define what kinds of instructors we want in the integrated mathematics courses.

We consider two mathematics skills important for engineering students. First, mathematics can be viewed as a language in engineering. As Gollish and Karney note, "mathematics, as it is taught to engineers, should be taught less as 'a means to an end' and more as a tool, specifically a communication tool" [12]. For example, differential equations are a language to describe dynamic relations of a system. Then, the teaching of mathematics can be similar to the teaching of a (foreign) language. That is, students need to become familiar with the new vocabulary and then use it in an engineering context. The transition from knowing a new word to using it in a sentence is often a non-separable package in the learning of a language.

The second mathematics skill is logical reasoning. Consider the bisection method for root finding as an example. Besides learning (and memorizing) the procedural details, one important experience is to understand why this method works (e.g., the condition of the starting range, the mechanism to choose one of two intervals, the terminating condition). This skill is about arranging several reasons logically for engineering problem solving.

In contrast to the aspects of language and logical reasoning, the scholarship of a mathematician often lies within the mathematics domain by developing mathematics concepts (e.g., uniqueness of solutions) and proving theorems (e.g., the intermediate value theorem for the bisection method). In contrast, engineers are skilled in describing systems (i.e., contextual language), and synthesizing logical reasons for solving an engineering problem (i.e., the logical reasoning skill). This highlights why the pilot in ENER 480, with both a mathematics instructor and an engineering instructor, provides students with a greater breadth of mindsets for approaching problem solving. In the end, the integrated mathematics approach has initiated some discussion about the essential mathematics elements important to engineering students and consideration of changes to the way we have been teaching mathematics for decades.

\subsection{Student Feedback}

In October 2019 we distributed a survey for mental health and student supports research approved by the
CFREB (Conjoint Faculties Research Ethics Board). Although the students were not specifically asked about the integrated math approach in this survey, we felt it applicable to discuss one of the main results observed in the students' feedback on this survey.

The Spring and Summer terms at the University of Calgary are very fast-paced compared to a regular term. Each term is only about 6 weeks in length, and each course has 10-15 weekly contact hours. During these classes, ENER students are refreshing their mathematics knowledge while also trying to adjust to university-level course expectations. Students have found adapting to all this change even more challenging given the fast-paced nature. For example, students were asked generally about their experience with the Schulich School of Engineering so far (after 5 months in the program), and one student said: "I understand that the summer semester is so that we can catch up, but the amount of material that we have to learn so quickly does not set us up for success." Many other students commented on the "condensed" and "fast" nature of the program being a difficulty for them. That being said, students are still generally positive about the program as a whole, "Although the program is tough, I am enjoying my time at the University of Calgary as I am learning a lot and enjoying what I am learning."

\section{NEXT STEPS}

Despite some minor challenges with its implementation, the integrated mathematics curriculum has proven to meet the needs of the B.Sc. in Energy Engineering program and its students. A key indicator of its success is in the second year of the program when B.Sc. in Energy Engineering students join senior (4 ${ }^{\text {th }}$ year) courses with the B.Sc. in Mechanical Engineering and the B.Sc. in Chemical Engineering cohorts where they successfully apply their mathematics skills alongside students from our regular, high-school admission programs.

As we move forward with the B.Sc. in Energy Engineering program, we will continue to monitor its students' achievement of mathematics-related learning outcomes. This process has involved regular meetings with the program's curriculum committee as well as meetings with faculty involved in teaching the integrated mathematics courses.

Following on the ENER 480 pilot with department of mathematics faculty, we hope to engage department of mathematics faculty more closely in the program in the future: both from a curriculum planning perspective as well as a teaching methods (pedagogy) perspective.

\section{Acknowledgements}

The authors wish to thank the Natural Sciences and Engineering Research Council, Spartan Controls, the 
Suncor Energy Foundation, and Schulich School of Engineering for their generous support of this research.

\section{References}

[1] S. Abramovich and A.Z. Grinshpan, "Teaching mathematics to non-mathematics majors through applications," PRIMUS, vol. XVIII, no. 5, pp. 411428, 2008.

[2] Alberta Council on Admissions and Transfer, Available as of January 3, 2020 from https://acat.alberta.ca/.

[3] Alberta Government, "Campus Alberta factsheet", Alberta Ministry of Advance Education Report, Available as of January 3, 2020 from https://open.alberta.ca/dataset/571115ce-51b1-4542a4c5-4738c4e6c805/resource/3b6f13b5-0238-4b8bbed5-3eda7852fe19/download/campus-alberta-factsapril-2013.pdf.

[4] T. Belytschko, A. Bayliss, C. Brinson, S. Carr, W. Kath, S. Krishnaswamy, B. Moran, J. Nocedal, and M. Peshkin, "Mechanics in the Engineering First curriculum at Northwestern University," International Journal of Engineering Education, vol. 13, no. 6, 1998.

[5] Camosun College Engineering Bridge, Available as of January 3, 2020 from http://camosun.ca/learn/ programs/engineering-bridge/.

[6] Canadian Engineering Accreditation Board, 2019 Accreditation Criteria and Procedures, Available as of January 3, 2020 from https://engineerscanada.ca/sites/ default/files/accreditation/Accreditation-CriteriaProcedures-2019.pdf.

[7] R. Carr, D.H. Thomas, T.S. Venkataraman, A.L. Smith, M.A. Gealt, R. Quinn, and M. Tanyel, "Mathematical and scientific foundations for an integrative engineering curriculum," Journal of Engineering Education, pp. 137-150, April 1995.

[8] Conestoga Pathways to your Success, Available as of February 8, 2020 from https://www.conestogac.on.ca/ engineering-technology/pathways

[9] C.T.J. Dodson, "Engineering mathematics bridges," Proceedings of the 1990 American Society for Engineering Education Annual Conference \& Exposition, 1990.

[10] J.E. Froyd and M.W. Ohland, "Integrated engineering curriculum," Journal of Engineering Education, pp. 147-164, January 2005.
[11] S. Gollish, "An investigation into mathematics for undergraduate engineering education to improve student competence in important mathematical skills," PhD Thesis, University of Toronto, 2019.

[12] S. Gollish and B. Karney, "Measuring the connection between mathematics and engineering," Proceedings of the Canadian Engineering Education Association, June 3-6, 2018.

[13] L.E. Grinter, "Report on evaluation of engineering education," Journal of Engineering Education, pp. 2560, 1955

[14] J.R. Hundhausen and R. Yeatts, "An experiment in integration: calculus and physics for freshmen," Journal of Engineering Education, pp. 369-374, October 1995.

[15] A. Kahanlari, "Engaging prospective engineers in math education through robotics and knowledge building," Proceedings of the Canadian Engineering Education Association, 2019.

[16] B. Karney, S. Gollish, and A. Mather, "A decisionmaking framework for engineering mathematics education: a critical literature review," Proceedings of the Canadian Engineering Education Association, June 4-7, 2017.

[17] B. Karney and A. Mather, "Math, policy and responsible action," Engineering Dimensions, pp. 4649, September/October 2011.

[18] T.R. Kelley and J.G. Knowles. A conceptual framework for integrated STEM education. International Journal of STEM Education, 3(1), 11, 2016.

[19] N.W. Klingbeil, R.E. Mercer, K.S. Rattan, M.L. Raymer, and D.B. Reynolds, "Rethinking engineering mathematics education: a model for increased retention, motivation and success in engineering," Proceedings of the 2004 American Society for Engineering Education Annual Conference \& Exposition, 2004.

[20] S. Kumar and J.A. Jalkio, "Teaching mathematics from an applications perspective," Journal of Engineering Education, pp. 275-279, July 1999.

[21] Lakehead University College Transfer Program, Available as of February 3, 2020 from https://www.lakeheadu.ca/programs/faculties/engineer ing/college-transfer-program.

[22] A. Schoenfeld, Mathematical Problem Solving, Academic Press, New York, 1985.

[23] C.A. Waldo, "The relation of mathematics to engineering," Science, vol. XIX, no. 478, pp. 321-330, February 1904 